\title{
Confronting Words: Driving a New Legal Lexicon of Disability
}

\author{
Rosalind F Croucher
}

\begin{abstract}
This article is about words - the words used to describe people with disability and those who assist them. It confronts the problem of finding the right words, tackled in the ALRC inquiry into the legal recognition of people with disability and their exercise of legal capacity, reflective of the dignity of all people. It describes the challenge of developing a 'new lexicon' in conjunction with developing National Decision-Making Principles, and places this in the historical context of the language of disability in law. It also recognises that, although changing language does not change everything, it is an important first step: to confront the confronting words.
\end{abstract}

In July 2013, the Australian Law Reform Commission (ALRC) was given Terms of Reference to consider the recognition of people with disability before the law and their exercise of legal capacity on an equal basis. In considering what, if any, changes to Commonwealth law could be made, the ALRC was directed to consider, among other things, 'the language used in laws and legal frameworks'.

In leading this important inquiry I knew from the first that we had to find a new lexicon. Looking at the language of disability in law is rather like undertaking a geological core drill. The eras of law's expression of disability are revealed through their terminology. So too is the social deployment of words in the pejorative. In short, we had to confront the confronting words.

In 1700, John Brydall, a writer of over 30 treatises, mainly on law, published Non Compos Mentis: or, the Law Relating to Natural Fools, Mad-Folks, and Lunatick Persons, Inquisited, and Explained for Common Benefit. Brydall's analysis was a technical one. Law had different consequences depending on the category of 'non compos mentis' into which a person might fall.

A Man of Non sane Memorie, is termed among the Latines Infanus, Fatuus, Amens, Demens, Mente Captus Maniacus Furiosus, Stultus, Errore Mentis Affectus, a Rationis usu Destitutus Lunaticus; and non Compos Mentis; of which several Terms, the last of all is most sure and legal; and according to our English Legulesians or Lawyers, Non Compos Mentis is of four sorts: First, He that is an Idiot Born. Next, He that by Accident afterwards loseth his Wits: Thirdly, A Lunatick, that hath sometimes his Understanding, and sometimes not: Lastly, He, which by his own act depriveth himself of his right mind for a time, as a Drunkard. ${ }^{1}$

1 John Brydall, Non Compos Mentis: or, the Law Relating to Natural Fools, Mad-Folks, and Lunatick Persons, Inquisited, and Explained for Common Benefit (Printed by the assigns of Richard and Edward Atkins, Esquires, for Isaac Cleave, 1700) 5 . 
Law was concerned with preconditions and consequences: the ability to enter into contracts, make a will, to be a judge, to marry. In feudal times law was also concerned with matters such as custody of the person and custody of lands - the two were often intertwined.

Such distinctions continued throughout the 18th century. In William Blackstone's day, mid-18th century, the principal legal distinction was between 'lunatics' and 'idiots' - '[a]n idiot, or natural fool, is one that hath had no understanding from his nativity' and '[a] lunatic, or non compos mentis, is one who hath had understanding, but by disease, grief, or other accident hath lost the use of his reasons'. ${ }^{2}$ The censuses undertaken each decade in the latter part of the 19th century in England, in addition to such matters as the person's age, marital status and profession, collected information as to whether the person was: 'Deaf-and-Dumb'; 'Blind'; 'Imbecile or Idiot'; or 'Lunatic'.

But somewhere between the 17th and the 20th centuries, the words descended in their quality. They ceased being technical and became derogatory. ${ }^{3}$ Even the name of the institution for lunatics in London, the Hospital of Saint Mary of Bethlehem, generated its own contribution to the list of disparaging words: 'bedlam'.

By the early 20th century, a more benign and generic term was found in the language of 'unsound mind', as evident, for example, in the Commonwealth Electoral Act 1918 (Cth). ${ }^{4}$ In the international arena, the expressions that were used in the United Nations Declarations of 1971 and 1975 were 'mentally retarded persons' and 'disabled persons'. . (One cringes when one hears the phrase 'mentally retarded' now, and its pejorative short form, 'retard'.)

'There is a problem of language when dealing with people with disabilities', the ALRC stated in the 1989 report, Guardianship and Management of Property. 'Some expressions which used to be common are no longer used by those working in the field because they are regarded as having connotations which tend to lower the dignity of people with

2 William Blackstone, Commentaries on the Laws of England (University of Chicago Press, 1765) Vol 1, 294. 'Lunatic' was derived from the Latin 'luna' or moon. As Louise Harmon explains, it embodied the idea that 'like the moon, the insanity of the lunatic waxed and waned. Even a lunatic who appeared permanently insane was presumed potentially curable. He had once lived his life on equal mental footing with others, and there was always that glimmer of hope that he would do so again': Louise Harmon, 'Falling off the Vine: Legal Fictions and the Doctrine of Substituted Judgment' (1990) 100(1) Yale Law Journal 1, 16.

3 A similar shift is evident in relation to the terms applying to children born out of wedlock: from 'bastards' to 'illegitimate' to 'ex-nuptial'.

4 For the historical background see, for example, Rosalind Croucher, "'An Interventionist, Paternalistic Jurisdiction"? The Place of Statutory Wills in Australian Succession Law' (2009) 32(3) University of New South Wales Law Journal 674.

5 Declaration on the Rights of Mentally Retarded Persons, GA Res 2856, UN GAOR, 3rd Comm, 26th sess, UN Doc A/RES/2856 (20 December 1971); Declaration on the Rights of Disabled Persons, GA Res 3447, UN GAOR, 3rd Comm, 30th sess, UN Doc A/RES/3447 (9 December 1975). 
disabilities.' 6 The ALRC therefore took an approach in that report which was to adopt usages 'current among people who are disabled and those who work with them'. ${ }^{7}$

When the ALRC was given the inquiry in 2013, a quarter of a century later, the language had shifted even further in the intervening years. By 2007, the collective phrase adopted in the international arena was 'persons with disabilities' in the Convention on the Rights of Persons with Disabilities (CRPD). ${ }^{8}$

As the ALRC had done in the 1989 report, in the 2013 inquiry we sought to frame concepts and choose terms in ways that reflected the framing principle of 'dignity'. Consistent with the approach identified by the ALRC in 1989, words and terms should not be used that tend to lower the dignity of people with disability.

Even where terms had an established usage, ${ }^{9}$ we considered that the development of a new lexicon was needed to signal the paradigm shift reflected in the CRPD - the purpose of which is to "promote, protect and ensure the full and equal enjoyment of all human rights and fundamental freedoms by all persons with disabilities, and to promote respect for their inherent dignity'. ${ }^{10}$ This inquiry provided an opportunity to contribute to that process. The key thing we sought to do was to place the emphasis in law, and in language, on support.

One of our challenges was that, as a Commonwealth body, our focus is necessarily on Commonwealth law - and yet so much of the laws concerning people with disability, and their practical operation, happen at State and Territory level. This is where the modelling aspect of our Terms of Reference really came into its own. We were asked to consider how maximising individual autonomy and independence could be modelled in Commonwealth laws and legal frameworks'. ${ }^{11}$ We concluded that this could best be achieved by setting out principles and guidelines that might then be used as a template for specific reforms. These principles and guidelines can be applied to Commonwealth and State and Territory laws - in particular, guardianship and administration laws. Central to

6 Australian Law Reform Commission, Guardianship and Management of Property, Report 52 (1989) [1.3].

7 Ibid.

8 Convention on the Rights of Persons with Disabilities, opened for signature 30 March 2007, 2515 UNTS 3 (entered into force 3 May 2008) (CRPD). Even this phrase is not universally accepted. Paul Harpur analyses the 'split between the USA/Australian and UK approaches to describing the interactions between impairments and society' and the increased use of the former since the adoption of the CRPD: Paul Harpur, 'From Disability to Ability: Changing the Phrasing of the Debate' (2012) 27(3) Disability \& Society 325, 327.

9 In the 1989 report, the ALRC gave the following example: 'The problem is complicated by the fact that the medical profession has adopted some words as having reasonably precise meanings but the same words are used differently by non-medical people or are regarded as inappropriate': above $n$, [1.3].

10 CRPD Art 1.

11 Australian Law Reform Commission, Equality, Capacity and Disability in Commonwealth Laws, Report 124 (2014) 7 (emphasis added). 
our recommendations were the National Decision-Making Principles and a Commonwealth decision-making model.

The Principles were expressed as essential goals to guide the reform of relevant Commonwealth, State and Territory laws. These are:

Principle 1: The equal right to make decisions

All adults have an equal right to make decisions that affect their lives and to have those decisions respected.

Principle 2: Support

Persons who require support in decision-making must be provided with access to the support necessary for them to make, communicate and participate in decisions that affect their lives.

Principle 3: Will, preferences and rights

The will, preferences and rights of persons who may require decisionmaking support must direct decisions that affect their lives.

Principle 4: Safeguards

Laws and legal frameworks must contain appropriate and effective safeguards in relation to interventions for persons who may require decision-making support, including to prevent abuse and undue influence. ${ }^{12}$

These principles reflect the paradigm shift signalled in the CRPD to recognise people with disability as persons before the law and their right to make choices for themselves. The emphasis is on the autonomy and independence of persons with disability who may require support in making decisions - their will and preferences must drive decisions that they make, and that others make on their behalf.

These four general principles reflect the key ideas and values upon which the ALRC's approach is based. They are drawn from the CRPD, other international models, stakeholder submissions and the work of other bodies and individuals. They are not prescriptive, and are of general application.

To encourage supported decision-making at a Commonwealth level, the ALRC recommends a new model (the Commonwealth decision-making model) based on the positions of 'supporter' and 'representative'. These terms are also part of building a new lexicon for supported decision-making. The role of both supporters and representatives is to assist persons who need decision-making support to make decisions in relevant areas of Commonwealth law. Recommendations are made about amending the objects or principles provisions in relevant Commonwealth legislation; the appointment, recognition, role and duties of supporters and representatives; and appropriate and effective safeguards. ${ }^{13}$

The term 'supporter' is used in the ALRC's model to reflect the role played by an individual or organisation that provides a person with the necessary support to make a decision or decisions. The term reflects the nature of the role, and indicates that ultimate decision-making power and responsibility remains with the person, with support being provided to assist them in making the decision themselves.

$12 \quad$ Ibid Recommendation 3.

13 See in particular $\mathrm{Ch} 4$. 
The term supporter is used by the Victorian Law Reform Commission (VLRC) in its Guardianship report. ${ }^{14}$ The VLRC described a supporter as a 'new legal mechanism'. A supporter:

[C]ould assist some people with impaired decision-making ability to continue to exercise legal capacity. Unlike substitute decision makers, supporters would not have the power to make decisions on behalf of a person, but they would be authorised to do certain things to assist the person to make their own decision. ${ }^{15}$

The new term, 'representative', is used in our Commonwealth decisionmaking model. ${ }^{16}$ 'Representative' was preferred over 'nominee' to signal the shift from existing decision-making arrangements in areas of Commonwealth law, including the National Disability Insurance Scheme and social security, both of which use the term nominee. Further, in circumstances where a person who may require decision-making support has not chosen or 'nominated' the person, the term nominee does not appropriately reflect the nature of the appointment.

The incorporation of a 'representative' in the model was an acknowledgment - and acceptance - that there is a point at which the idea of supporting a person to make decisions is no longer practically possible. At this point we recommended the introduction of representatives as a mechanism for this in areas of Commonwealth law, but this came with limits: a representative should only be appointed as a last resort and in limited circumstances. A representative under the model is an individual or organisation appointed by a person who requires decision-making support, or through some other appointment mechanism. The guiding aspect in the duties of the representative was that of the will and preferences of the person being represented. ${ }^{17}$ This may be contrasted with the 'best interests' standard that still applies in relation to substitute decision-making pursuant to some guardianship and administration laws.

We chose the word 'representative' with considerable care. We needed to distance ourselves from the historical baggage of 'guardianship' and find a word that was anchored in the concept of a 'will and preferences' model. In settling upon the word 'representative', I drew upon my research background in succession law where the 'legal personal representative', in particular the executor, acts in execution of what the deceased person wanted: they literally represent the deceased through the discharge of the intentions of the deceased expressed in the person's will.

In considering the recognition of people with disability before the law and their exercise of legal capacity on an equal basis, the disability

14 Victorian Law Reform Commission, Guardianship, Final Report 24 (2012) Recommendation 30.

15 Ibid 126. The Powers of Attorney Act 2014 (Vic), enacted in August 2014, implements some of the VLRC's recommendations in creating the role of a 'supportive attorney': see Powers of Attorney Act 2014 (Vic) Pt 7.

16 This formulation is currently used under the Personally Controlled Electronic Health Records Act 2012 (Cth). The term representative is also used in other jurisdictions, for example, Representation Agreement Act, RSBC 1996, с 405.

Embodied in Recommendation 4-8. 
inquiry made us confront the words: 'the language used in laws and legal frameworks'. We worked our way through each word, each concept and each principle, assisted throughout by an Advisory Committee and the appointment as a part-time Commissioner of then Disability Discrimination Commissioner, Graeme Innes. ${ }^{18}$

It was a deeply reflective and respectful process, and we embraced the task of proposing a new lexicon as the opportunity to make a singular contribution in this crucial field. We recognised, however, that changes in language, as in law, of themselves, do not effect change, but it is important. As remarked in one submission: 'Changing laws and implementing new policies regarding legal capacity is only the first step in realising the right to equal recognition before the law for people with disability.' ${ }^{19} \mathrm{~A}$ first step, but a monumental one: to confront the confronting words.

18 The list of Advisory Committee members and all those consulted in the inquiry is included in the report. All public submissions are found on the ALRC website at $<$ https://www.alrc.gov.au/inquiries/disability/submissions $>$.

19 People with Disability Australia, Australian Centre for Disability Law and Australian Human Rights Centre, Submission 36, July 2014, [15]. Others who supported this approach included ACT Disability, Aged and Carer Advocacy Service, Submission 108, 2014. 